\title{
A PROFISSÃO DE ENFERMAGEM NO SÉCULO XXI ${ }^{1}$
}

\author{
THE NURSING PROFESSION IN THE XXI CENTURY \\ LA ENFERMERIAA EN EL SIGLO XXI
}

Maria Helena Machado²

\begin{abstract}
RESUMO: O presente artigo apresenta a análise sociológica da profissāo de enfermagem enfocando as especificidades da profissão a partir dos elementos constitutivos de uma profissão segundo o construto teórico da sociologia das profissões.Ao final do século $X X$ e ínício do novo milênio a enfermagem se depara com questōes cruciais da profissão que recoloca a necessidade de reestruturar as considerações estratégicas que compōem a agenda politica da corporação. Saber específico, qualificaçăo profissional, especificidades do processo de trabalho, monopólio do exercício profissional, conformação da equipe hierarquizada de enfermagem, são alguns dos itens que este artigo aborda. Sendo uma das profissōes essenciais da saúde, a enfermagem necessita chegar ao próximo século com nova perspectiva de como e que condições vai exercer o oficio no contexto de mudanças paradigmáticas. Desta forma, uma agenda politica da corporaçăo terá que contemplar os vários aspectos constitutivos de uma profissăo, ou seja, saber especifico, mercado exclusivo de trabalho, forma de organização, entre outros.
\end{abstract}

PALAVRAS CHAVE: profissão de enfermagem, profissão e saúde, especificidades da enfermagem, enfermagem e trabalho

\section{UMA DEFINIÇÃO DE PROFISSÃO}

Pensar os sistemas de profissões no mundo moderno nos convida a refletir sobre o processo em que se conformou os grupos profissionais, que, mais tarde, seriam denominados de profissões. Autores como Goode (1969) e Abbott (1988) advertem para a seguinte questão: o processo de profissionalização não advém de uma história natural mas de um contexto históricoestrutural. É deste ponto de vista que estudiosos como Larson (1977), Donnangelo (1975), Mckinlay; Arches (1986), Powell (1985), Haug (1989), Oppenheimer (1975), Machado (1996), entre outros, defendem a tese de que corporaçōes tradicionais tais como médicos, advogados, engenheiros e enfermeiros experimentam hoje fortes mudanças na sua especificidade profissional. Estes autores analisam o crescente assalariamento, as interferências do poder público e das modernas estruturas organizacionais do setor privado, as mudanças tecnológicas no mundo do trabalho que estes "profissionais liberais" vêm experimentando nas últimas décadas. Mckinlay e Arches (1986) têm a opinião de que estes profissionais estão tornando-se "proletários" ou seja, estão perdendo definitivamente a autonomia técnica e econômica. Ressaltam também, que essas transformações não são fenômeno exclusivo de alguns países, mas das sociedades em geral que atingiram um nível de desenvolvimento econômico e tecnológico elevado e que passa a reger as relações de trocas no mercado de trabalho

Mas o que seria um processo de profissionalização? Quais são os elementos constitutivos que compōem este processo que originaria uma profissão?

\footnotetext{
'Texto originalmente apresentado no 60" Semana de Enfermagem, Curitiba, maio de 1999.

${ }^{2}$ Socióloga, doutora em sociologia, pesquisadora da Escola Nacional de Saúde Pública, Fiocruz
}

R. Bras. Enferm., Brasilia, v. 52, n.4, p. 589-595, out./dez. 1999 
Utilizando a definição parsoniana de profissão, podemos dizer que profissões são sistemas de solidariedade cuja identidade é assegurada na competência técnica de seus membros, obtida em instituições de ensino credenciadas para este fim. Desta forma, profissionais são aqueles individuos que possuem domínio sobre um determinado conhecimento com forte racionalidade cognitiva aplicável em uma dada realidade. Nesta perspectiva, o conhecimento especifico tem um realce particular, definindo condutas técnicas e áreas de aplicabilidade dessa base cognitiva. Tal concepção sociológica de Parsons enfatiza os grupos profissionais à semelhança dos existentes nos sistemas de guildas portadoras àquela época, de maior status. Afirma Barbosa (1993), "que sendo assim, os profissionais tenderiam a apresentar dois tipos de orientação nas suas ações: um ideal de serviço que os distinguiria dos negociantes orientados para o mercado, e um padrão associativo diferente daquele existente nas organizações burocráticas e daquele mais orientado para o mercado". Desta forma, a ação profissional tenderia a superar esses dois pólos. O ponto central das profissões passa a girar em torno dos atores, ou seja, na relação interacional entre produtor (profissional) e cliente, tornando-se modelo de ação social no qual os atores desempenham papéis muito bem definidos.

Por outro lado, este conceito funcionalista evoluiu recebendo contribuições importantes a partir da década de 1950. Wilbert Moore (1970) contribui para que a sociologia elabore e sistematize um arcabouço teórico-metodológico nesse campo. Destaca a complexidade em conceituar profissionalismo por ser dificil identificar o modelo ideal ou as características essenciais de uma categoria ocupacional que a distinga claramente de outras. Buscando resolver esta questão metodológica, o autor sugere que a melhor maneira de identificar um profissional seria oferecendo uma escala de atributos sociológicos, retirando do fórum de debates a rígida classificação entre os individuos que exercem uma profissão ou uma semi-profissão ${ }^{3}$. Apesar de não considerarmos relevante esta classificação sugerida pelo autor entre o que profissão e semi-profissão é interessante no entanto, a escala de atributos que ele apresenta, uma vez, que a profissão que ora analisamos sofre de inconsistência na construção de sua base cognitiva, como veremos mais a frente.

O que seria esta escala de atributos?

Primeiro, aqueles individuos que atuam em uma atividade o fazem em tempo integral e vivem da remuneração proveniente dessa ocupação.

Segundo, estes individuos se destacam pela vocação. Aceitam normas e modelos profissionais apropriados e identificam-se com seus colegas, mantendo uma forte noção de coletividade. Tornar-se profissional requer a adoção deste espirito de corpo que dá ao grupo a exata noção de pertencer a uma "sociedade secreta" dotada de regras e normas sociais referentes à vida profissional comum destas pessoas. O sentimento vocacional é considerado como elemento fundante da profissão.

Terceiro, a partir de mútua identificação de interesses corporativos organizam-se em

\footnotetext{
${ }^{3}$ Uma profissão é definida como tal, quando possui um corpo específico de conhecimento para atuar numa dada realidade social organizada. A medicina, a advocacia, a odontologia, engenharia, etc., são, nesta perspectiva, consideradas "profissões". Já a enfermagem, a farmácia, serviço social, por exemplo, são consideradas na literatura sociológica como semi-profissões. Tal diferenciação teórico-metodológica é aplicável, no segundo caso, fundamentalmente pela ausência de um corpo conhecimento fechado e restrito, bem como a ausência de definição efetiva de mercado de trabalho específico, exclusivo e resenvado através do monopólio da prática profissional. Este segundo grupo de atividades profissionais teria dificuldades em delimitar esses campos que salientamos acima. Numa situação intermediária, buscando firmar-se como profissão estão a sociologia, psicologia, a ciência da computação, entre outras atividades profissionais emergentes. Estas categorias estariam consolidando sua base cognitiva e assım se organizando para obter exclusividade de atuação profissional.
} 
entidades próprias para terem estrito controle sobre o acesso, o recrutamento, a projeção e a regulamentação dos membros, adotando um código de ética para toda a comunidade profissional. Sendo assim, a organização dos interesses tende a orientar-se por ações políticas: por problemas mundanos e por considerações estratégicas. A primeira refere-se às questões ligadas ao mundo do trabalho, à remuneração, às lutas e reivindicações trabalhistas, etc.. A segunda, refere-se às questões relacionadas à ética, à base cognitiva, à produção do conhecimento especifico, à divulgação, à proteção e à delimitação do território profissional, bem como à identificação de interesses comuns. Ambas no entanto, assumem crucial importância na orientação política da corporação.

Quarto, a aquisição de um corpo de conhecimento formal, transmitido nas escolas (licenciadas pelo Estado), è um outro atributo-chave. Apesar de existirem variações entre os projetos profissionais, a educação formal serve de base para a maioria das ocupações nas sociedades modernas se firmar e constituir-se em áreas especificas de atuação no mercado de trabalho. Com essa base teórica, o profissional torna-se apto a prestar serviços especializados no seu campo de atuação. Receberá, portanto, o passaporte para o mercado de trabalho.

Quinto, a atividade deverá ter um forte apelo por servir à coletividade, de um ideal de serviço (Goode, 1967). A noção de utilidade social, de utilidade pública é de suma importância para se obter o monopólio do saber e da prática profissional. É necessário delimitar e definir, através de normas e códigos de ética, a conduta da corporação, assegurando homogeneidade e qualidade técnicas nos serviços prestados. A transmissão de confiança no serviço é essencial na venda do produto profissional, permitindo que a profissão se estabeleça definitivamente no mercado de serviços. Tornar-se útil, socialmente relevante e confiável perante os clientes, são elementos chaves para o sucesso profissional de qualquer profissão que queira se firmar no mercado de trabalho.

Sexto, a autonomia técnica e econômica representam os elementos mais caracteristicos de uma atividade profissional. No entanto, para que uma profissão obtenha autonomia é preciso estabelecer critérios claros tais como: evidência do trabalho oferecido: compromisso vocacional; organização e controle de admissão de novos membros; educação especializada e normas efetivas que assegurem execução competente de serviços. Consolidou-se na sociedade contemporânea de que demonstrar conhecimento, habilidades e destrezas especificas permitem que uma determinada categoria profissional adquira credibilidade social e reivindique do Estado prerrogativas monopolistas.

Em sua análise sociológica, Moore (1970) salienta que o grau de profissionalização de uma profissão é medido pelo grau de êxito na reivindicação de competência técnica exclusiva e pelo grau de apelo ao ideal de trabalho e pelas suas normas de apoio à conduta profissional".

Freidson (1978) por sua vez, toma como ponto central da argumentação, a relação entre prática e o conhecimento (saber) que, segundo ele, é fonte geradora de poder e autonomia. Os profissionais destacam-se pelo fato de terem formação universitária, com credenciamento para atuar em mercados especificos e exclusivos, quase sempre. As corporações se organizam para obter essa jurisdição junto ao Estado e à própria sociedade (clientela). ${ }^{4} \mathrm{E}$, desta forma, credencia-se para ser a única fonte de competência para reconhecer uma atuação inadequada, equivocada e, ao mesmo tempo, se auto-regular. Sua autonomia é justificada e comprovada pela auto-regulação (Freidson, 1978).

Dessa maneira, o Estado passa a ser um forte aliado concedendo o direito de monopólio do exercicio profissional. Excluir concorrentes significa, entre outras estratégias, fazer aliança com o Estado e, através de mecanismos legais assegurar domínio daquela categoria profissional.

${ }^{4}$ Freidson (1978, p 145-63) centra sua análise na questão da autonomia profissional, associando-a a obtenção de conhecimento especializado do grupo profissional. 
Alicerçada num conhecimento especifico, somente ela poderá executar tais serviços e mais, estes, serão regulados pela própria corporação mediante um refinado código de ética do exercicio profissional elaborado, aprovado e controlado pela própria profissão.

Enfim, chamamos de profissão, quando os individuos praticam uma ocupação em tempo integral; há um forte componente vocacional; possui estrutura de organização aos moldes de uma corporação; estabelece um código de ética; desenvolve um saber específico; possui uma forte orientação para serviço e mantém um alto grau de autonomia no trabalho (Machado, 1996).

Concluindo, duas características sociológicas básicas distinguem profissão de ocupação no mercado de trabalho: Primeiro, o caráter técnico da atividade, que pressupõe um corpo de conhecimento sistemático adquirido por meio de um treinamento sistematizado e estandardizado. Segundo, a existência de normas e regras profissionais que orientam seu trabalho. Em outros termos, a atividade terá que reunir um conjunto de atos sistemáticos, contínuos que obedecerão a uma certa lógica técnica científica. Sendo assim, qualquer profissão que pretenda exercer autoridade profissional terá de encontrar uma base técnica para fazê-lo, reivindicar que tanto os procedimentos técnicos como a jurisdição estejam de acordo com padrões de treinamento e, convencer o público de que seus serviços são exclusivamente confiáveis. Torna-se estratégico que o público leigo sinta necessidade e confiança para buscar seus serviços especializados, tornando-se consumidores potenciais. No entanto, dizer técnico não é o mesmo que dizer científico, pois a base da reivindicação de sua competência exclusiva varia de acordo com caracteristicas distintas das funções e formação de cada profissão, analisa Wilensky (1970).

\section{AS ESPECIFICIDADES DA PROFISSÄO DE ENFERMAGEM}

Quando falamos de profissão, nos referimos ao conceito sociológico que define profissão como sendo uma atividade exercida por pessoas com destreza e habilidades especificas capaz de desenvolver um determinado trabalho com autonomia técnica. A literatura internacional como já nos referimos, salienta a importância desses elementos constitutivos como fundantes da profissionalização.

A profissão de enfermagem como a medicina fazem parte das profissões essenciais a qualquer sistema de saúde que pressupōe atendimento de qualidade e alicerçada em um processo de trabalho moderno e tecnicamente aceitável em sociedades desenvolvidas. O que queremos dizer é que a enfermagem é uma profissão essencial, de utilidade pública, de valor social inquestionável.

Mas vejamos o caso da enfermagem que, devido a sua conformação requer do sociólogo que vai analisá-la alguns cuidados teórico-metodológicos.

A forte participação feminina, oriunda de segmentos sociais questionáveis (religiosas, damas e mulheres da vida mundana) faz da profissão uma atividade com problemas adicionais. As mulheres, historicamente, ingressaram no mercado de trabalho tardiamente em todas as esferas produtivas. $O$ trabalho feminino precisou de um longo tempo para ser reconhecido publicamente como trabalho remunerado. No caso da enfermagem, o oficio não se constituiu em uma atividade rigorosamente profissional, ou seja, os atos e serviços não seguiram a um padrão de remuneração de mercado. Damas, religiosas e mulheres da vida mundana não exerciam o oficio por dinheiro. A tradição se manteve por longo periodo e, hoje a corporação tem ainda dificuldades em estabelecer valores pré-determinados para os atos praticados, como fazem os médicos, por exemplo. Nenhuma das entidades da corporação apresentou até o momento uma tabela de honorários profissionais que pudesse regular a prestação de seus serviços. Da mesma forma, a determinação de jomada de trabalho e salários compativeis ainda são pontos da agenda política pouco discutidos e esclarecidos.

No entanto, há uma contradição nesta especial composição de gênero que apresenta a enfermagem e o processo de trabalho a que este contigente profissional está submetido. Sendo 
constituida em sua maioria por mulheres, o processo de trabalho de enfermagem bem como as jornadas de trabalho, quase sempre em formato de turnos, se assemelham muito mais as jornadas proposta há décadas passadas pelos ferroviários, quando então estabeleceram os turnos de trabalho continuos, descansando após uma longa jomada de 12 horas. Neste sentido, a enfermagem e toda sua equipe, constituida quase que exclusivamente de mulheres, acabam adotando esquemas de trabalho muito assemelhados à estrutura masculina, sobrecarregando em muito sua vida pessoal. Em outras palavras, o trabalho de enfermagem é exaustivo, intensivo e incompatível com as especificidades da própria condição feminina.

A enfermagem adquiriu enorme conhecimento empirico do ambiente de trabalho, seja ele ambulatorial ou hospitalar. É de seu escopo profissional, o domínio do quotidiano do paciente e do ambiente hospitalar onde, na realidade, os fatos e as situações relevantes se desenvolvem. Com isso, a enfermagem passa a deter informações privilegiadas sobre vários aspectos: relação médico-paciente; ambiente hospitalar, poder e dinâmica institucionais; administração hospitalar; direção clínica e gerencial; relação profissional/profissional, etc.. No entanto, este vasto e rico campo de prática adquirido ao longo dos tempos, não resultou no monopólio do conhecimento desta realidade. Em outras palavras, a enfermagem não soube resguardar nichos de saber e prática profissionais para a obtenção prerrogativas monopolistas.

Por outro lado, histórica e estruturalmente os enfermeiros sempre requereram ao longo de sua existência forte apoio de equipe correlata - equipe de enfermagem - hierarquizada e subordinada tecnicamente aqueles profissionais diplomados. Tal fato fez da enfermagem uma profissão que experimenta na própria estrutura interna, forte concorrência, não só na divisão de trabalho como e principalmente na disputa por mercado de serviços de enfermagem, dificultando sua efetiva profissionalização. Atualmente, o Brasil conta com mais de 700 mil profissionais atuando nesta equipe de enfermagem, sendo que apenas $10 \%$, ou seja, em torno de 70 mil são enfermeiros.

Em nossa opinião, a constituição da equipe de enfermagem antes de ter representado um avanço na estruturação do processo de trabalho, tornou-se marca registrada de uma profissão com várias facetas e vários niveis ocupacionais que fazem mais ou menos a mesma coisa, especialmente na visão do cliente que recebe cuidados de enfermagem. O questionamento sobre a pertinência ou não e até mesmo, a manutenção da composição atual da equipe ou seja, enfermeiros, técnicos, auxiliares de enfermagem e atendentes, deverá ser incluída, prioritariamente na agenda para o próximo século. Nos tempos da modernidade, será mesmo necessário e justificável uma equipe com esta composição?

Por outro lado, a profissão de enfermagem acabou tendo pouca sustentação cognitiva, ou seja, uma atividade profissional com forte conteúdo prático e pouco conteúdo teórico. 0 saber da enfermagem não se constitui em um saber específico, fechado em si como uma "caixa preta", o que a faz muito frágil perante a concorrência no mercado de serviços de saúde, quando esta reivindica monopólio de exercício profissional. Nesta esfera, a enfermagem acaba sendo compelida a disputar mercado de trabalho com as chamadas ocupações afins, ou seja, com os técnicos e auxiliares de enfermagem. Este tem sido o problema estratégico mais importante que a profissão experimenta em seu quotidiano de trabalho.

A questão da autonomia técnica é de fato um problema adicional para a enfermagem que se vê com forte dependência do trabalho médico, tornando uma atividade com reduzida autonomia profissional. Poucas são aquelas atividades que são executadas sem a coordenação técnica do médico. Um conjunto de atividades de enfermagem que são executadas com autonomia relativa, em sua maioria, é realizada pelo pessoal de linha da enfermagem, permitindo assim a execução destas com transparência para além do estrategicamente desejável. Com alta visibilidade do processo de trabalho, os enfermeiros acabam tendo dificuldades adicionais para concretizar o processo de profissionalização. A idéia de que o trabalho do enfermeiro (diplomado) pode ser executado por ocupações da enfermagem, promove, no imaginário social, a visão de que o 
enfermeiro não é essencial à sociedade, como ocorre com os médicos. A reivindicação de monopólio e exclusividade no exercicio profissional acaba tornando-se um discurso ideológico de difícil convencimento. A enfermagem ainda não desenvolveu sua expertise profissional, permitindo que muitos executem seu trabalho de forma irregular.

Da mesma forma, a profissão desenvolveu forte dependência do trabalho assalariado em instituições de saúde, seja no setor público ou privado, tornando-se assim, uma atividade com reduzida autonomia econômica. Poucos săo os profissionais que exercem atividades de forma liberal. A manutenção de consultório não é uma rotina incorporada pelos enfermeiros.

Concluindo, a profissão de enfermagem anuncia-se para o século XXI com questões importantes a serem debatidas e esclarecidas, não só porque tais questões afetam seu quotidiano profissional como e principalmente porque dessas questöes de ordem estratégicas representam a reformulação da agenda politica da corporação para consolidar definitivamente o processo de profissionalização.

\begin{abstract}
The present article presents the sociological analysis of the nursing profession, focussing the specificities of the profession on the basis of the component elements of a profession, according to the theoretical system of the sociology of professions. At the end of the 20th century and the beginning of the new millenium, nursing faces crucial questions for the profession, which bring back the need to restructure the strategic considerations that make up the political agenda of the nursing profession. Specific knowledge, professional qualification, particularities of the work process, monopoly of the professional exercise, and the configuration of the hierarchy of the nursing team are some of the items dealt within this article. As one of the essential professions in the health area, nursing needs to reach the next century with a new perspective, knowing how and in which conditions it will develop in a context of paradigmatic changes. Considering this new context, a political agenda for nursing professionals will have to contemplate the several aspects that make up a profession, that is. specific knowledge, exclusive labor market, form of organization, among others.
\end{abstract}

KEYWORDS: nursing care, parents, preterm newborn

RESUMEN: El presente articulo presenta un analisis sociológico de la profesión de enfermeria enfocando sus especificidades a partir de los elementos constitutivos de una profesión, según el constructo teórico de la sociologia de las profesiones. Al final del siglo XX e inicio del nuevo milenio, la enfermeria tiene ante si temas cruciales de la profesión, que apuntan hacia la necesidad de reestruturar estrategias que componen la agenda politica de la corporación. Saber especifico, calificación profesional, especificidades del proceso de trabajo, monopolio del ejercicio profesional, conformación del equipo hierarquizado de enfermeria son algunos de los puntos que el articulo trata. Al ser una de las profesiones esenciales de la salud, la enfermeria tiene que llegar al próximo siglo con nueva perspectiva de cómo y en qué condiciones se ejercerá el oficio en un contexto de cambios paradigmáticos. De esa forma, una agenda politica de la corporación tendrá que contemplar los varios aspectos constitutivos de una profesion, como el saber especifico, el mercado exclusivo de trabajo y la forma de organización, entre otros

PALABRAS CLAVE: profesión de enfermeria, profesión de salud, especificidades de la enfermeria, enfermeria y trabajo 


\section{BIBLIOGRAFIA}

ABBOTT, Andrew. The System of Professions. An Essay on the Division of Expert Labor. London and Chicago: The University of Chicago Press, 1988.

FREIDSON, Eliot. La Profesion Médica. Un Estudio de Sociologia del Conocimiento Aplicado. Tradução de Maria Isabel Hirsch. Barcelona: Ediciones Peninsula, 1978.

FREIDSON, Eliot. Are Professions Necessary? In: Thomas L. Haskell (Org.), The Authority of Experts. Studies in History and Theory. Bloomington: Indiana University Press, 1984.

LARSON, Magali Sarfatti. The Rise of Professionalism. A Sociological Analysis. Berkeley, Los Angeles and London: University of California Press, 1977.

Proletarianization and Educated Labor. Theory and Society, vol. 9, p. 131-175, 1980.

MACHADO, Maria Helena. Os Médicos e sua prática profissional: as metamorfoses de uma profissão. Rio de Janeiro, Tese (Doutorado) - IUPERJ.

MACHADO, Maria Helena et al. Os médicos no Brasil - um retrato da realidade. Rio de Janeiro: ed. FIOCRUZ, 1997

MENDES, E. V. A Evolução Histórica da Prática Médica; suas implicações no ensino, na pesquisa e na tecnologia médicas. Belo Horizonte: PUC - MG/FINEP, 1984

MOORE, Wilbert E. The Professions. Roles and Rules. New York: Russel Sage Foundation, 1970.

SANTOS NETO, Pedro Miguel dos. O Processo de Profissionalização Médica em Pernambuco: um Estudo sobre a Categoria Médica Pernambucana, sua Organizaçāo, seus Interesses. Rio de Janeiro, 1993. Tese (Mestrado) - Escola Nacional de Saúde Pública/Fiocruz.

SCHRAIBER, Lilia Blima. O Médico e seu Trabalho. Limites da Liberdade. São Paulo: Editora Hucitec, 1993.

STARR, Paul. La Transformación Social de la Medicina en los Estados Unidos de América. Tradução de Agustin Bárcena. México: Fondo de Cultura Económica, 1991.

WILENSKY, H. L. The Professionalization of Everyone?. In: Oscar Grusky \& George Miller (Orgs.). The Sociology of Organizations: Basics Studies. New York: The Free Press, 1970. 